\title{
Remotely coupled surface plasmons in a metal/insulator/Si structure perforated with periodic square hole arrays
}

\author{
Tzu-Hung Chuang, Ming-Wei Tsai, Yi-Tsung Chang, and Si-Chen Lee ${ }^{\text {a) }}$ \\ Department of Electrical Engineering, Graduate Institute of Electronics Engineering, \\ National Taiwan University, Taipei, Taiwan 106, Republic of China
}

(Received 17 March 2006; accepted 26 May 2006; published online 20 July 2006)

\begin{abstract}
The zero-order transmission of radiation through a metal/dielectric structure perforated with square hole arrays is strongly enhanced when incident light resonates with surface plasmons (SPs). Surprisingly, when a metal/dielectric double layer, such as $\mathrm{Ag} / \mathrm{SiO}_{2}$, is fabricated on a silicon substrate, the Ag/Si SP mode by coupling Ag and Si across the intermediate dielectric film has been found. It is named the remotely coupled surface plasmon. The transmission intensity is investigated as a function of the intermediate $\mathrm{SiO}_{2}$ thickness. The coupling lengths between $\mathrm{Ag}$ and $\mathrm{Si}$ in order to form the Ag/Si SP mode are determined as well, and they turn out to be 500 and $130 \mathrm{~nm}$ for couplings through air and a $\mathrm{SiO}_{2}$ layer, respectively. (C) 2006 American Institute of Physics.
\end{abstract}

[DOI: $10.1063 / 1.2234290]$

Surface plasmons (SPs) are longitudinal waves that propagate along the surface of a conductor, usually a metal. When a metal film is perforated with two-dimensional periodic square hole arrays, it exhibits extraordinary optical transmission because of SP resonance. ${ }^{1,2}$ Numerous studies have explored the fundamental properties of the SPs and their potential applications in devices. ${ }^{3-13}$ Experimental and analytical results indicate that tunneling through surface plasmons formed on each metal-dielectric interface enhances transmission. ${ }^{3-8}$ According to theoretical analyses, if the perforated metal film has symmetric interfaces, then SPs at the top and bottom interfaces are coupled via evanescent waves. ${ }^{9}$ Extraordinary optical transmission in the middle and far infrared regions has been demonstrated. ${ }^{10-13}$ Our results further indicate that when a metal/dielectric double layer, such as $\mathrm{Ag} / \mathrm{SiO}_{2}$, is fabricated on the silicon substrate, the $\mathrm{Ag} / \mathrm{Si} \mathrm{SP}$ mode is established by coupling $\mathrm{Ag}$ and $\mathrm{Si}$ across the $\mathrm{SiO}_{2}$ thin film in the middle infrared region. This mode is called the remotely coupled surface plasmon (RCSP) mode. The intensity of the $\mathrm{Ag} / \mathrm{Si} \mathrm{RCSP}$ mode is investigated as a function of the intermediate $\mathrm{SiO}_{2}$ thickness and the coupling length between $\mathrm{Ag}$ and $\mathrm{Si}$ is extracted. Additionally, the multipeak transmission through a triple layer, such as $\mathrm{Ag} / \mathrm{SiO}_{2} / \mathrm{TiO}_{2}$ fabricated on the silicon, is also demonstrated.

The photoresist was spun on the silicon wafer and the square hole array was defined and opened. Then, $\mathrm{SiO}_{2}$ and Ag films were deposited and then lifted off. The thickness of the Ag film was fixed at $100 \mathrm{~nm}$ and the lattice constant of the hole arrays was $5 \mu \mathrm{m}$. A Bruker IFS $66 \mathrm{v} / \mathrm{S}$ system was used to measure the zero-order transmission spectra. The wave number resolution of the measurement was $8 \mathrm{~cm}^{-1}$. The sample was defined to lie in the $(x, y)$ plane, and the light was incident in the $z$ direction.

The momentum conservation law of SPs is given by

$$
\mathbf{k}_{\mathrm{SP}}=\mathbf{k}_{x}+i \mathbf{G}_{x}+j \mathbf{G}_{y}
$$

where $\mathbf{k}_{\mathrm{SP}}$ is the surface plasmon wave vector,

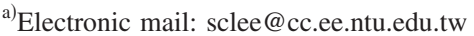

$$
\left|\mathbf{k}_{\mathrm{SP}}\right|=\frac{\omega}{c}\left(\frac{\varepsilon_{1} \varepsilon_{2}}{\varepsilon_{1}+\varepsilon_{2}}\right)^{1 / 2} .
$$

Here, $\mathbf{k}_{x}=\left|\mathbf{k}_{0}\right| \sin \theta ;\left|\mathbf{k}_{0}\right|=2 \pi / \lambda$ is the wave vector of the incident radiation, $\lambda$ is the wavelength in vacuum, and $\theta$ is the angle between the incident radiation and the $z$ direction. $\mathbf{G}_{x}$ and $\mathbf{G}_{y}$ are the reciprocal lattice vectors of a square lattice with $\left|\mathbf{G}_{x}\right|=\left|\mathbf{G}_{y}\right|=2 \pi / a$, where $a$ is the lattice constant, and $i$ and $j$ are integers. In Eq. (2), $\omega$ is the frequency of the SP that is excited by the incident radiation with frequency $\omega$, and $\varepsilon_{1}$, and $\varepsilon_{2}$ are the dielectric constants of the insulator and the metal, respectively. For normally incident light, $\mathbf{k}_{x}=0$, Eq. (2) is reduced to

$$
\lambda=a\left(i^{2}+j^{2}\right)^{-1 / 2}\left(\frac{\varepsilon_{1} \varepsilon_{2}}{\varepsilon_{1}+\varepsilon_{2}}\right)^{1 / 2} .
$$

The real parts of the dielectric constant of $\mathrm{Ag}$ at 5, 8, and $17 \mu \mathrm{m}$ are $-1.31 \times 10^{3},-3.32 \times 10^{3}$, and $-1.44 \times 10^{4},{ }^{14}$ respectively. The dielectric constants of $\mathrm{SiO}_{2}$ and $\mathrm{Si}$ at those wavelengths are 2.45 and 11.7. Therefore, theoretically, the degenerate $( \pm 1,0)$ and $(0, \pm 1)$ of air/Ag, $\mathrm{Ag} / \mathrm{SiO}_{2}$, and $\mathrm{Ag} / \mathrm{Si}$ modes are at 5, 7.8, and $17.1 \mu \mathrm{m}$ when the lattice constant of the hole arrays is $5 \mu \mathrm{m}$. Figure 1(a) shows the optical transmission of the $\mathrm{Ag} / \mathrm{SiO}_{2} / \mathrm{Si}$ periodic hole array of sample A in which the $\mathrm{SiO}_{2}$ is also perforated, as shown in the inset. The diameter of each hole is $3.5 \mu \mathrm{m}$. Three main transmission peaks are observed at 5, 7.8, and $17.2 \mu \mathrm{m}$ in Fig. 1(a). They correspond to the air/Ag, $\mathrm{Ag} / \mathrm{SiO}_{2}$, and $\mathrm{Ag} / \mathrm{Si} \mathrm{SP}$ modes, respectively. The $\mathrm{Ag} / \mathrm{Si} \mathrm{SP}$ mode is redshifted by $0.1 \mu \mathrm{m}$ from its theoretical values, as will be discussed later. The transmission dip at $9.3 \mu \mathrm{m}\left(1070 \mathrm{~cm}^{-1}\right)$ is caused by $\mathrm{SiO}_{2}$ absorption. Although a $\mathrm{SiO}_{2}$ layer is present between the $\mathrm{Ag}$ and $\mathrm{Si}$ films, the $\mathrm{Ag} / \mathrm{Si} \mathrm{SP}$ mode clearly exists when the $\mathrm{SiO}_{2}$ layer thickness is thin enough. Thus, it is called remotely coupled SP. The SP waves are not only excited by light at the interface between the metal and dielectric but also remotely coupled to the other dielectric across the neighboring one. That is, collective charges on the metal surface induced by light can remotely induce charges on the dielectric at a distance and satisfy the dispersion relation of the SP. The transmitted intensity of the Ag/Si RCSP 

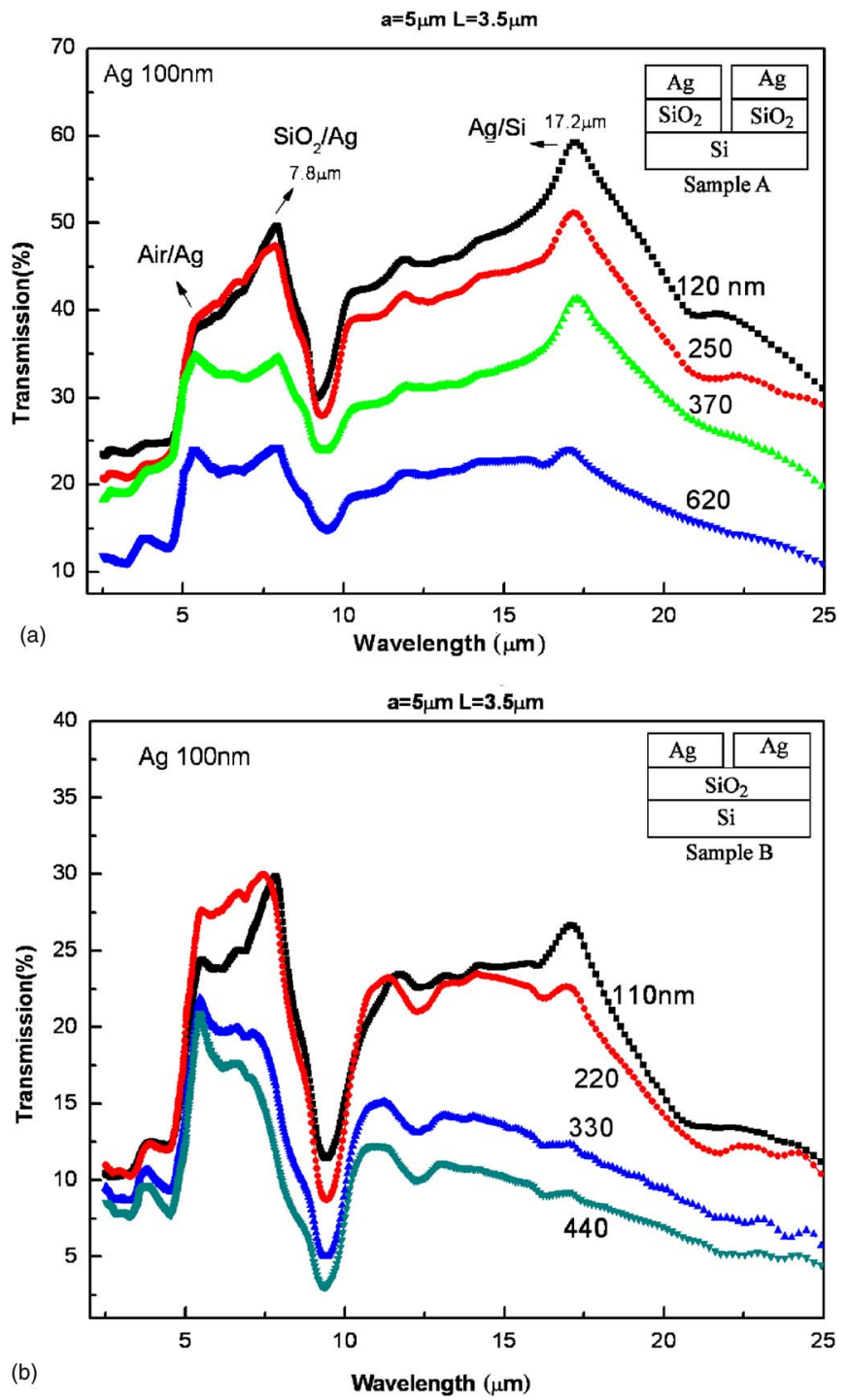

FIG. 1. (Color online) Zero-order transmission spectra of (a) sample A and (b) sample B with different $\mathrm{SiO}_{2}$ thicknesses. The lattice constant $a$ is $5 \mu \mathrm{m}$ and the hole diameter $L$ is $3.5 \mu \mathrm{m}$. In sample B, the perforated holes are only in the top metal layer.

mode decays as the thickness of $\mathrm{SiO}_{2}$ increases. Hence, the data can be fitted using an exponential function to determine the decay length of the coupling, as shown in Fig. 2. The respective peak transmissions at different $\mathrm{SiO}_{2}$ thicknesses are obtained by subtracting the transmission intensity at the off-resonance wavelength of $3 \mu \mathrm{m}$ from the peak transmission of the $\mathrm{Ag} / \mathrm{Si}$ mode at $17.2 \mu \mathrm{m}$. The coupling length of the RCSP is defined as the thickness of the $\mathrm{SiO}_{2}$ layer, the corresponding peak transmission in the fitting curves of which goes to $e^{-1}$ of the original value at zero $\mathrm{SiO}_{2}$ thickness. The fitting functions are also shown in Fig. 2, and $X$ and $Y$ represent the $\mathrm{SiO}_{2}$ thickness and the peak transmission, respectively. The coupling length for sample A is $500 \mathrm{~nm}$. The intensity of the $\mathrm{Ag} / \mathrm{SiO}_{2}$ mode also decreases as the thickness of $\mathrm{SiO}_{2}$ increases. The variation is attributed to the strong absorption of $\mathrm{SiO}_{2}$ at $9.3 \mu \mathrm{m}$. Figure 1(b) shows the optical transmission of sample $\mathrm{B}$ with different $\mathrm{SiO}_{2}$ thicknesses. In sample $\mathrm{B}$, the $\mathrm{SiO}_{2}$ layer is not perforated as shown in the inset. The lattice constant and the hole diameter are the same as those of sample A. Similarly, the $\mathrm{Ag} / \mathrm{Si}$ RCSP mode can still be seen if the thickness of the Downloaded 04 Mar 2009 to 140.112 .113 .225 . Redistribution subje

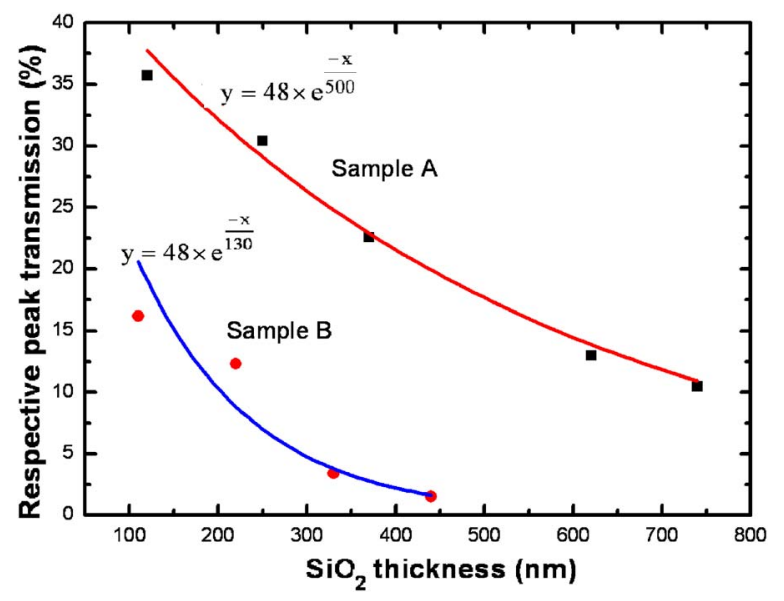

FIG. 2. (Color online) Fitting curve of the $\mathrm{Ag} / \mathrm{Si}$ mode transmission of samples A and B.

$\mathrm{SiO}_{2}$ layer is less than $440 \mathrm{~nm}$. The $\mathrm{Ag} / \mathrm{Si}$ RCSP mode also decays as the $\mathrm{SiO}_{2}$ thickness increases. The coupling length of the $\mathrm{Ag} / \mathrm{Si} \mathrm{RCSP}$ mode is much shorter if the $\mathrm{SiO}_{2}$ film is not perforated, as shown in Fig. 2. The coupling length of sample B is $130 \mathrm{~nm}$. Therefore, the coupling mechanism of RCSPs primarily involves the holes. Figure 3 shows the optical transmission of sample A with differently sized holes, $L=4,3.5$, and $3 \mu \mathrm{m}$. The thickness of the $\mathrm{SiO}_{2}$ is fixed at $740 \mathrm{~nm}$. The Ag/Si RCSP mode appears when the diameter of the hole exceeds $3.5 \mu \mathrm{m}$. Thus, the coupling length of the RCSP also depends on the size of the hole.

Figure 4 plots the optical transmission of samples $\mathrm{C}$ and $\mathrm{D}$, which have the triple layer structure- $\mathrm{Ag} / \mathrm{TiO}{ }_{2} / \mathrm{SiO}_{2}$ for sample $\mathrm{C}$ and $\mathrm{Ag} / \mathrm{SiO}_{2} / \mathrm{TiO}_{2}$ for sample $\mathrm{D}$ - and are fabricated on the $\mathrm{Si}$ wafer, as shown in the inset. It also plots the optical transmission of sample E, which has a double-layered $\mathrm{Ag} / \mathrm{TiO}_{2}$ structure. The dielectric constant of the $\mathrm{TiO}_{2}$ is 4.0. The transmission curve of sample $\mathrm{E}$ reveals that the air/Ag and $\mathrm{Ag} / \mathrm{TiO}_{2}$ modes are at 5 and $10 \mu \mathrm{m}$, values which are consistent with theory. The peak at $19.0 \mu \mathrm{m}$ is the $\mathrm{Ag} / \mathrm{Si}$ RCSP mode and will be discussed later. For samples $\mathrm{C}$ and $\mathrm{D}$, the $\mathrm{TiO}_{2}$ and $\mathrm{SiO}_{2}$ layers are clipped between the $\mathrm{Ag}$ film perforated with holes and the Si wafer. Four main peaks on the transmission curve are observed, as shown in Fig. 4. These are identified as air/Ag, $\mathrm{Ag} / \mathrm{SiO}_{2}, \mathrm{Ag} / \mathrm{TiO}_{2}$, and $\mathrm{Ag} / \mathrm{Si}$ modes. Therefore, the multipeak transmission can be

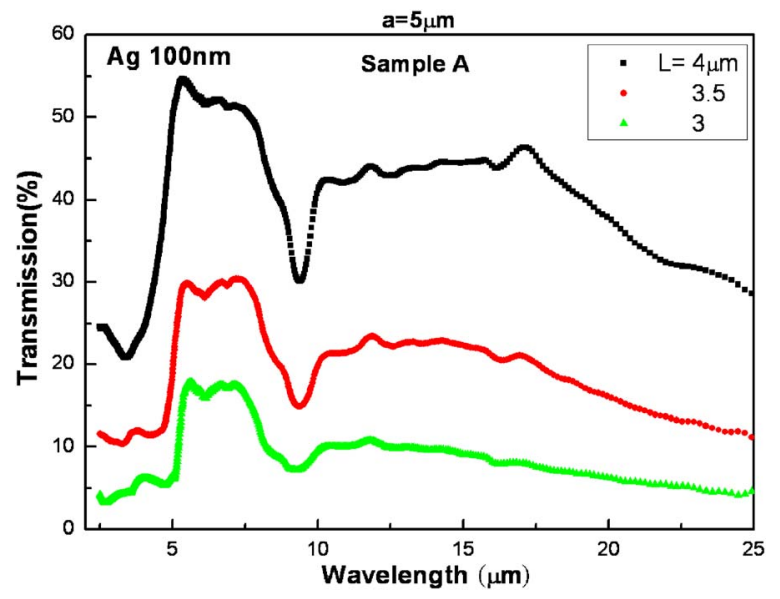

FIG. 3. (Color online) Zero-order transmission spectra of sample A with holes of various sizes. The thickness of $\mathrm{SiO}_{2}$ is fixed at $740 \mathrm{~nm}$.

to AIP license or copyright; see http://apl.aip.org/apl/copyright.jsp 


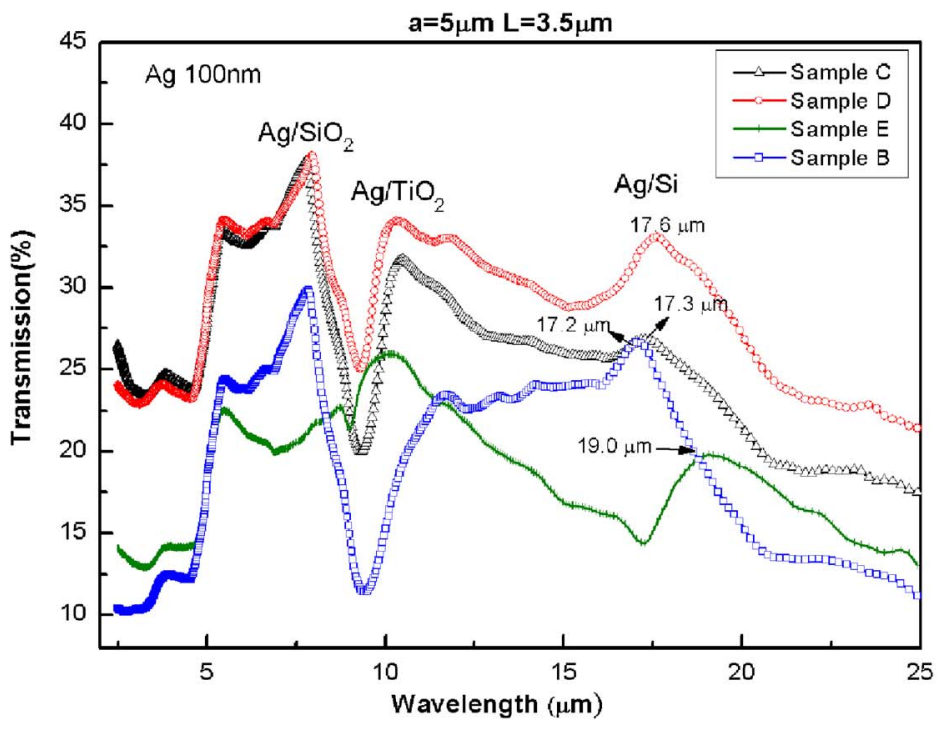

achieved by clipping appropriate materials with various dielectric constants between the perforated Ag film and $\mathrm{Si}$ wafer. The structural difference between samples $\mathrm{C}$ and $\mathrm{D}$ is the sequence of deposition of the $\mathrm{TiO}_{2}$ and $\mathrm{SiO}_{2}$ layers. Clearly, the respective transmission intensities of the $\mathrm{Ag} / \mathrm{SiO}_{2}$ and $\mathrm{Ag} / \mathrm{TiO}_{2}$ modes change little when the deposition sequence of the two layers is interchanged. Therefore, the multipeak transmission intensity achieved by RCSPs is independent of the sequence of the intermediate dielectric material. The $\mathrm{Ag} / \mathrm{Si}$ RCSP mode is shifted to slightly longer wavelengths when the intermediate layer between $\mathrm{Ag}$ and $\mathrm{Si}$ is changed to a material with a higher dielectric constant. For example, the larger dielectric constant of $\mathrm{TiO}_{2}$ (4.0) than that of $\mathrm{SiO}_{2}$ (2.45) causes a Ag/Si RCSP mode in sample E to yield a peak at $19.0 \mu \mathrm{m}$ rather than at $17.2 \mu \mathrm{m}$ in sample B. If double layers are present between the $\mathrm{Ag}$ and $\mathrm{Si}$, the peak transmission wavelength depends on the percentage of double dielectrics or the effective dielectric constant. In sample $\mathrm{C}$, the percentage of the $\mathrm{TiO}_{2}$ layer in the intermediate is smaller than that of sample D. Therefore, the peak of the Ag/Si RCSP mode in sample C $(17.3 \mu \mathrm{m})$ is at a shorter wavelength than that in sample D $(17.6 \mu \mathrm{m})$.

In conclusion, the $\mathrm{Ag} / \mathrm{Si} \mathrm{SP}$ mode by coupling $\mathrm{Ag}$ and $\mathrm{Si}$ across the intermediate dielectric thin film through the holes has been found. The decay length of the RCSP is affected by not only the thickness of the dielectric film, whether perforated or not, but also the size of holes in the metal. The peak transmission wavelength of the RCSP is affected by the effective dielectric constant of the material between the Ag and Si substrates. A larger effective dielectric constant corresponds to a larger redshift of the peak trans-

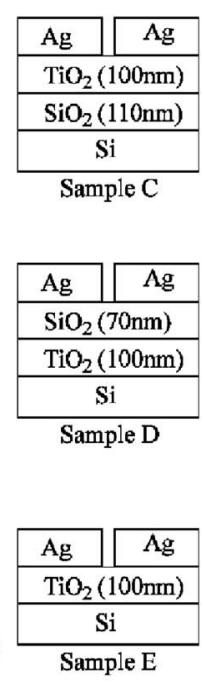

FIG. 4. (Color online) Zero-order transmission spectra of samples $\mathrm{C}$ to E. The lattice constant $a$ is $5 \mu \mathrm{m}$ and the hole diameter $L$ is $3.5 \mu \mathrm{m}$. mission wavelength. Furthermore, the Ag/Si RCSP coupling lengths were 500 and $130 \mathrm{~nm}$ for couplings through air and a $\mathrm{SiO}_{2}$ layer, respectively.

The authors would like to thank the National Science Council of the Republic of China for financially supporting this research under Contract No. NSC 94-2215-E-002-042.

${ }^{1}$ H. F. Ghaemi, Tineke Thio, D. E. Grupp, T. W. Ebbesen, and H. J. Lezec, Phys. Rev. B 58, 6779 (1998).

${ }^{2}$ T. W. Ebbesen, H. J. Lezec, H. F. Ghaemi, T. Thio, and P. A. Wolff, Nature (London) 391, 667 (1998).

${ }^{3}$ L. Martin-Moreno, F. J. Garcia-Videl, H. J. Lezec, K. M. Pellerin, T. Thio, J. B. Pendry, and T. W. Ebbesen, Phys. Rev. Lett. 86, 1114 (2001).

${ }^{4}$ J. Gomez Rivas, C. Schotsch, P. Haring Bolivar, and H. Kurz, Phys. Rev. B 68, 201306(R) (2003).

${ }^{5}$ Dongxia Qu, D. Grischkowsky, and Weili Zhang, Opt. Lett. 29, 896 (2004).

${ }^{6}$ William L. Barnes, Alain Dereux, and Thomas W. Ebbesen, Nature (London) 424, 824 (2003).

${ }^{7}$ S. A. Darmanyan and A. V. Zayats, Phys. Rev. B 67, 035424 (2003).

${ }^{8}$ W. L. Barnes, W. A. Murray, J. Dintinger, E. Devaux, and T. W. Ebbesen, Phys. Rev. Lett. 92, 107401 (2004).

${ }^{9}$ A. Krishnan, T. Thio, T. J. Kim, H. J. Lezec, T. W. Ebbesen, P. A. Wolff, J. Pendry, L. Martin-Moreno, and F. J. Garcia-Vidal, Opt. Commun. 200, 1 (2001).

${ }^{10}$ Shaum M. Williams, Amanda D. Stafford, Kenneth R. Rodriguez, Trisha M. Rogers, and James V. Coe, J. Phys. Chem. B 107, 11871 (2003).

${ }^{11}$ Shaun M. Williams, Amanda D. Stafford, Trisha M. Rogers, Sarah R. Bishop, and James V. Coe, Appl. Phys. Lett. 85, 1472 (2004).

${ }^{12}$ Y.-H. Ye and Jia-Yu Zhang, Appl. Phys. Lett. 84, 2977 (2004).

${ }^{13}$ Q. Cao and P. Lalanne, Phys. Rev. Lett. 88, 057403 (2002).

${ }^{14}$ M. A. Ordal, L. L. Long, R. J. Bell, S. E. Bell, R. R. Bell, R. W. Alexander, Jr., and C. A. Ward, Appl. Opt. 22, 1099 (1983). 